\title{
PROPOSED METHODOLOGY FOR ESTABLISHING AN EARLY GNSS WARNING SYSTEM FOR REAL-TIME DEFORMATION MONITORING
}

\section{METODOLOGÍA PARA EL ESTABLECIMIENTO DE UN SISTEMA DE ALERTA TEMPRANA GNSS PARA LA MONITORIZACIÓN DE DEFORMACIONES EN TIEMPO REAL}

\author{
Mutaz Qafisheha, ${ }^{a}$, Angel Martína, Raquel M. Capillab \\ ${ }^{a}$ Department of Cartographic Engineering, Geodesy and Photogrammetry, Universitat Politècnica de València, Camino de Vera s/n, \\ Valencia 46022, Spain. muqawa@doctor.upv.es, aemartin@upvnet.upv.es \\ ${ }^{b}$ Research section in Geomatics, Cartographic Institute of Valencia, Generalitat Valenciana, C/ de la Democràcia 77, Valencia 46018, \\ Spain. racaro@upv.es
}

\begin{abstract}
:
Early Warning System (EWS) for monitoring megastructures deformation, natural hazards, earthquakes, and landslides can prevent economic and life losses. Nowadays, Real-Time Precise Point Positioning (RT-PPP) plays a vital role in this domain since it relies on precise real-time measurements derived from a single receiver, provides real-time monitoring and global coverage. Nevertheless, RT-PPP measurements and methodology is very sensitive to outliers in products, latencies and changes in the constellation geometry. Consequently, there are long initialization periods, losses of convergence and different noise sources, with a high impact on the warning system's availability or even led out to initiate false warnings. This study presents the first experiment to propose a methodology that can help the decision-makers confirm the warning based on the probability of the detected movement by using machine learning classification models. For this, in the first experiment, a laser engraving machine device was modified to simulate deformations. A control unit will be designed based on open-source software, Python libraries are implemented, and the $\mathrm{G}$ programming language used to control the device motions. All this research will be the background on which the early warning service will be developed.
\end{abstract}

Key words: precise point positioning, machine learning, warning system, deformation monitoring

\section{Resumen:}

Los sistemas de alerta temprana para la monitorización de deformaciones de estructuras, terremotos, movimientos de ladera u otro riego natural pueden prevenir pérdidas económicas y de vidas. El Posicionamiento Preciso de Punto en tiempo real (RT-PPP) ha demostrado ser útil en este escenario ya que se basa en medidas de precisión a partir de un único receptor, proporcionando cobertura global en tiempo real. A pesar de esto, la técnica RT-PPP es muy sensible a la precisión de los productos usados, latencia y cambios en la geometría de la constelación. Así, los periodos largos de inicialización de la técnica, la pérdida de convergencia de la solución o las diferentes fuentes de ruido, generan un gran impacto en la disponibilidad de un sistema de alerta temprana, pudiendo incluso generar falsas alarmas. Este trabajo presenta los primeros experimentos para generar un sistema de confirmación sobre una alerta temprana a partir de la probabilidad de detectar movimiento usado modelos de clasificación basados en técnicas de aprendizaje automático. Para esto, en un primer experimento, una máquina de grabado láser ha sido modificada para simular deformaciones. Se ha desarrollado una unidad de control basada en software libre, librerías de Python y el lenguaje de programación $\mathrm{G}$ que sirve para controlar los movimientos de la máquina. Este trabajo será la base sobre la que desarrollar, en un futuro, un servicio de alerta temprana.

Palabras clave: posicionamiento puntual preciso, aprendizaje automático, sistema de alertas, monitorización de deformaciones

\section{Introduction}

Different surveying ways and earth observations such as levelling, electronic distance measurements, synthetic aperture radar (SAR), besides GNSS, are using in deformation detections. GNSS itself also has different methods for positioning and deformations detection (Blewitt et al. 2009; Jäger et al. 2005; Roberts et al. 1999). Those methods vary in terms of accuracy and availability. The EWS for monitoring natural hazards and deformation can establish using any of the pre-mentioned ways.
Accordingly, the pros and cons of these ways affect the availability and the accuracy of the EWS.

Currently, around 129 navigation satellites are operating under the GNSS umbrella and orbiting the earth planet (GPS.gov 2020; NovAtel Inc 2015). Positioning determination using GNSS can achieve using several ways, including Single Point Positioning, which is an autonomous way, differentially such as static, real-time kinematic, Virtual reference station, or Precise Point Positioning (PPP) (Enge and Misra 2011). Traditional GNSS high accuracy methods required operate at least a

*Corresponding Author: Mutaz Qafisheh, muqawa@doctor.upv.es 
couple of the GNSS receivers operating in the same region. Alternatively, to cover vast areas, it requires operating a network of GNSS receivers to establish differential GNSS surveying; consequently, it requires maintaining internet or radio connection, hosting server and powerful processor for corrections creation and transmitting. As a result, it required high cost to maintain and establish such a network (Rizos et al. 2012).

At the end of the late nineties in the last century, Zumberge introduced the PPP method (Zumberge et al.1997). The main pro of this method is that it can be implemented using a single GNSS receiver with decimetre level accuracy in real-time mode. This advantage clarifies that an early warning system relying on PPP measurements the only available solution for some areas.

Barker et al. (2002) studied different potential areas where PPP usage can take place, like offshore and remote areas. Those areas suffer from a lack of coverage of nearby base stations, or they are not covered by GNSS network solution or Virtual Reference Station (VRS). Isolated areas or regions with fewer infrastructures can take benefit from this technique.

The theoretical background behind the PPP solution contains high-precision pseudoranges and phase measurements composed with different corrections such as clock and orbital, phase and code biases and optionally ionospheric corrections (Rizos et al. 2012). Real-time PPP users can receive those corrections via the internet through different products, for instance, IGS01, IGS02 and IGS03, which are considered official IGS products (Johnston et al. 2017; International GNSS Service 2013). Additionally, different analysis centres and commercial companies produce their own individual products.

The PPP method is encountering several obstacles, for example, long converging time, corruption or discontinuity of the correction products. Moreover, the correction products themselves suffer latencies and corrections oscillations (Martín et al. 2013; Qafisheh et al. 2020). These difficulties affect the availability and readability of the EWS. So, the first thing to consider to establish the final warning system is to understand and correlate all variables involved in the observational process, their limitations, and the impact on the probability to accurately detect or not a deformation movement. The experiment described in this manuscript is related to the objective to become familiar with the GNSS receiver in conjunction with the Computer Numerical Control (CNC) machine to simulate movements, develop the required software, and study the correlations among the different parameters involved in the observation. All this knowledge will be the background for the forthcoming experiments that should lead to the development of the warning system.

\section{Methodology}

In this section, the research methodology divided into different steps and the flow of those steps organized to cover all the research objectives are introduced. Figure 1 shows the research methodology flow chart.

\subsection{Step 1}

Initially, the first step was designed to investigate the station location for collecting high-quality PPP observations. The investigation leads to establish a station on the roof of a building located in the southwest part of Hebron city in West Bank. The station has been chosen with an almost open sky view and lower multipath.

\subsection{Step 2}

The next step was dedicated to obtaining the station coordinates with a high accuracy method. Consequently, that guide us to observe the station through a static method. The static session has been holding on March 3 2021 , for 24 hours. The total number of satellites was 36 . The station coordinates were derived through the online positioning services provided by the US Department of Commerce (https://www.ngs.noaa.gov/OPUS/), NOAA, and National Geodetic Survey. The processing of the static data was repeated after two weeks to use the precise final correction products. Table 1 shows the derived coordinates with ITRF2014 at Epoch 2021.21 (Stone 2006).
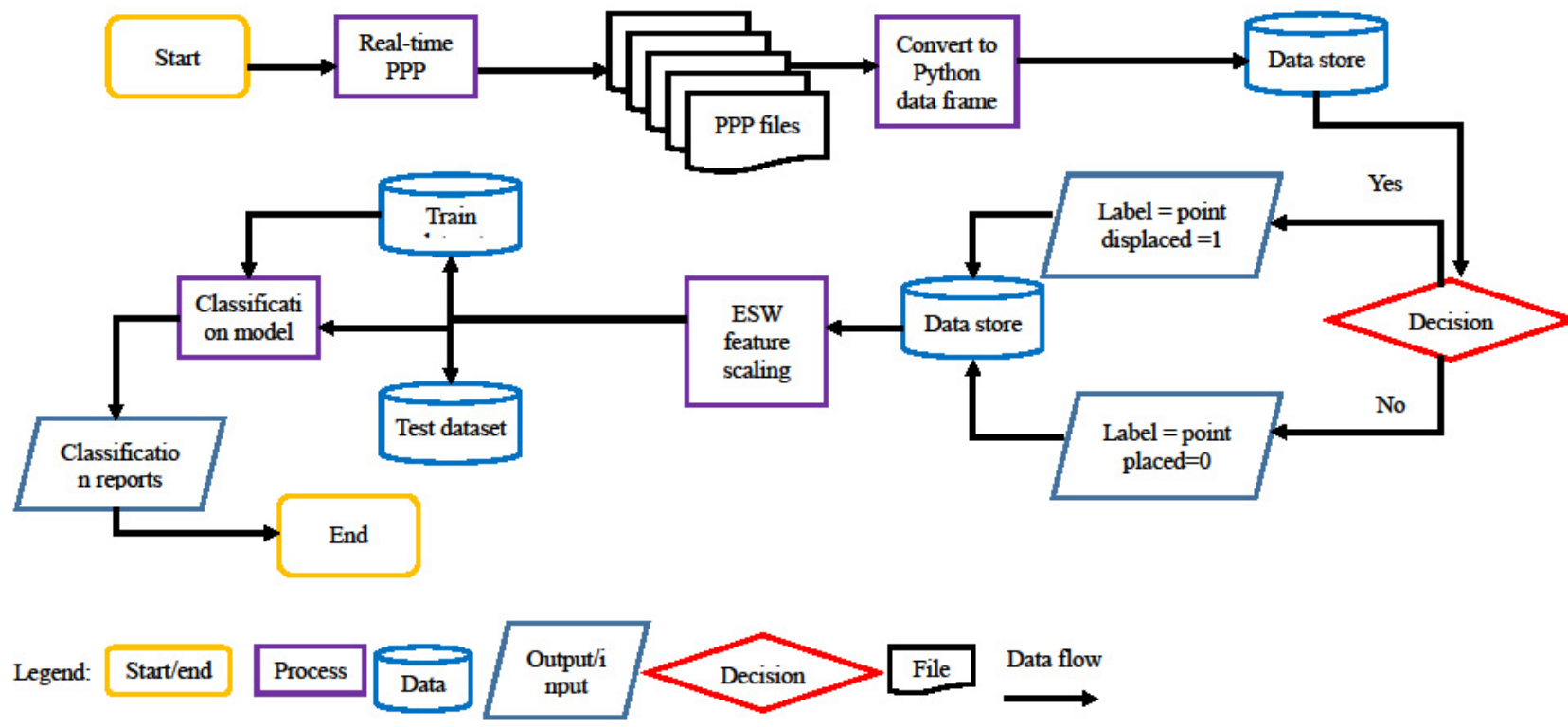

Figure 1: Research methodology flow chart. 
Table 1: ITRF 2014 polar coordinates for the experiment station.

\begin{tabular}{c|c|c|c}
$\begin{array}{c}\text { Station } \\
\text { name }\end{array}$ & Latitude $N$ & Longitude $E$ & Altitude $(m)$ \\
\hline Mutaz & $31^{\circ} 30^{\prime} 25.172^{\prime \prime}$ & $35^{\circ} 03^{\prime} 38.994 "$ & $915 \pm 0.009$ \\
& \pm 0.003 & \pm 0.003 &
\end{tabular}

\subsection{Step 3}

The third step, designed to obtain the first real-time observations, contains several tasks.

\subsubsection{Task 1}

The experiment platform contains a CNC machine fixed over a portable table. The table was set up over the station point marker; consequently, the horizontal and vertical level adjusted using circular and tubular vials. Cooperatively, the plump was attached to the GNSS receiver in order to ensure receiver centring. In this experiment, we face problems with the CNC machine controller; the clock equipped on this machine is suffering from the delay. The value of this delay varies, and it was not easy to predict. We overcome this problem by filming the entire observation session.

\subsubsection{Task 2}

This experiment was detected to collect GNSS observations with 20 centimetres in horizontal displacement. In order to do that, The CNC machine was loaded with 20 points having $X$ and $Y$ coordinate components in the machine coordinate system with a polar distance equal to the desired displacement. The point's components values shuffled in order to add randomization for receiver movements. Twenty centimetres is a movement that real-time PPP can detect good enough. Therefore, the results obtained allow us to get an idea about the minimum limit of movement that real-time PPP may be able to detect.

\subsubsection{Task 3}

The experiment was designed with 20 displaced points, regularly distributed around the origin station location. The GNSS receiver at the beginning had to be warmed up for 15 minutes over the true marker location in order to end the initialization period. Next, the receiver movement was designed to go back on forth from the displaced points and true marker location with a waiting time equal to 15 minutes in every displaced point and true marker.

\subsection{Step 4}

The PPP real-time observations were collected using code and phase measurement using GPS and GLONASS satellites. Several features had been driven from the observed data, such as horizontal dilution of precision, total satellite number, ionosphere error, latency, coordinate accuracy, and the magnitude of displacement relative to the a priori coordinates. All these parameters have been obtained using BNC software(Weber and Mervart 2007). Based on previous results (Martín et al. 2013; Qafisheh et al. 2020), a stream with a latency below 15 seconds should be used to obtain precise and accurate real-time PPP coordinates.

\subsection{Step 5}

In this step, Pandas (https://pandas.pydata.org) and Numpy (https://numpy.org) python libraries were used to read the BNC files. Consequently, the clock timestamp for each observation was added to the Numpy array. Then the Numpy array was converted to the Pandas data frame. The final output data frame contains 21 columns with 36713 rows (one row for every recorded epoch).

\subsection{Step 6}

Data cleaning and preparation is a crucial aspect for the correct implementation of the machine or deep learning techniques. One of the essential aspects of future experiments is data scaling. Machine learning Scikit learn library has a built-in function, which is useful for data scaling and can be implemented in many ways. Additionally, categorical and null data must be handled before building the model (SciKit-Learn 2016).

\subsection{Step 7}

In this step, Matplotlib is used for visualization, and Seaborne and Panda are used to understand data trends, directions and feature relations. The related software, based on those libraries, has been developed (Matplotlip 2012).

\subsection{Step 8}

Finally, in future experiments, different machine and deep learning classification models will be used with different data sample having various displacement values. The prepared model will test against different observation environments to provide the EWS users with the most appropriate observation conditions to initiate reliable and robust EWS.

\section{Data collection}

This experiment conducted on April 18 with 20 centimetres displacement value. The experiment was held for 10 hours long, The BNC software was used in real-time mode using the CLK93 correction stream (a stream with low latency), and the sampling frequency for NMEA and position intervals was $1 \mathrm{~Hz}$. At the end of the experiment, a total of 36713 GNSS points were collected.

BNC software uses the code/phase ionospheric combination to mitigate the ionospheric delay.

Other configurations related to observation noise, satellite cut off-angle, and the minimum number of observations required for positioning determination has been set.

Figure 2 shows the entire experiment collected data. The figure shows a scatter plot displaying the north and east displacements.

Figure 3 shows the evolution of the displacement with respect to time. The dash borders on the figure show the warm-up period require to end the initialization periods. The figure upper part shows the calculated displacements values when the receiver is displaced from the original location. In contrast, the lower part shows the calculated displacement when the receiver occupies the station marker. 


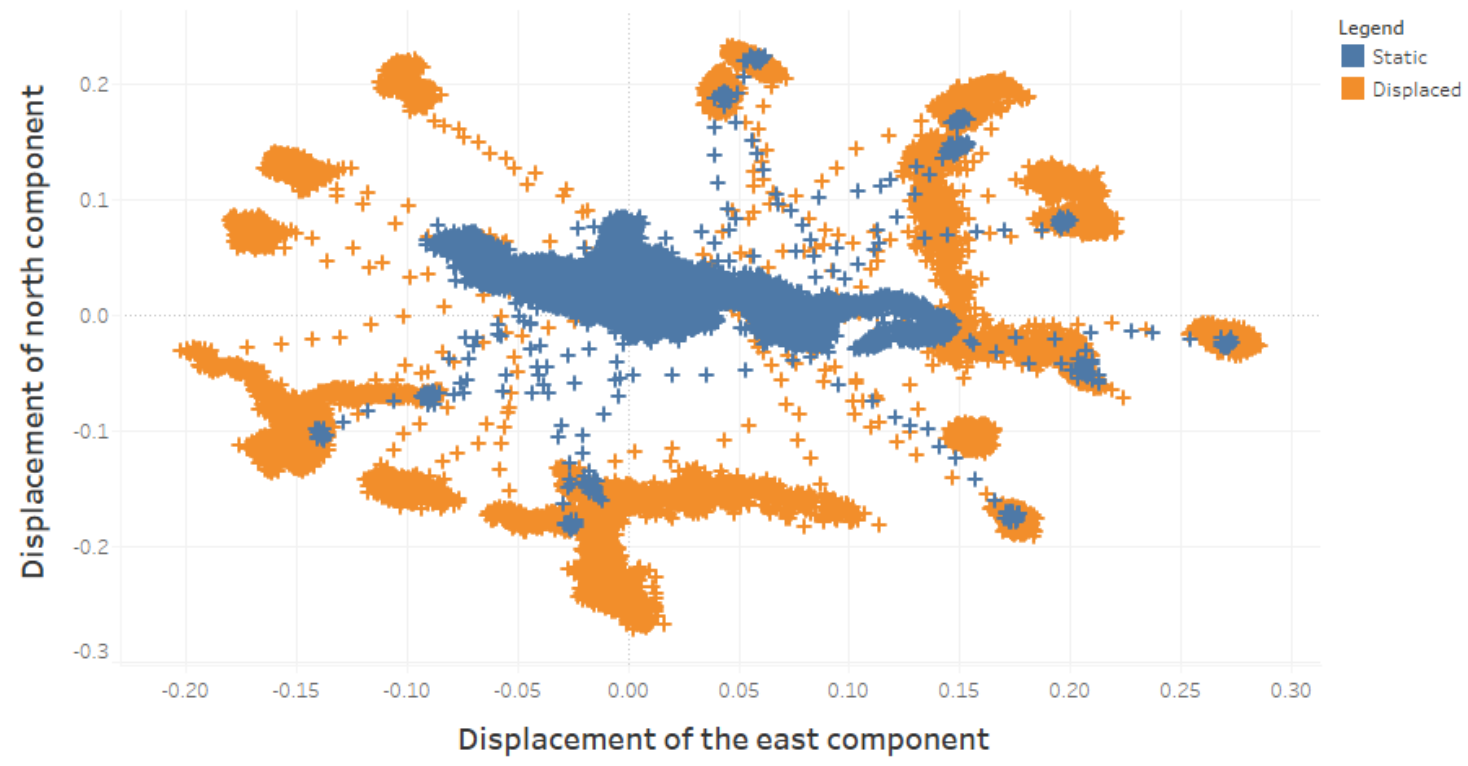

Figure 2: Static and displaced points scatter plot for all the observed points. Units are in meters.

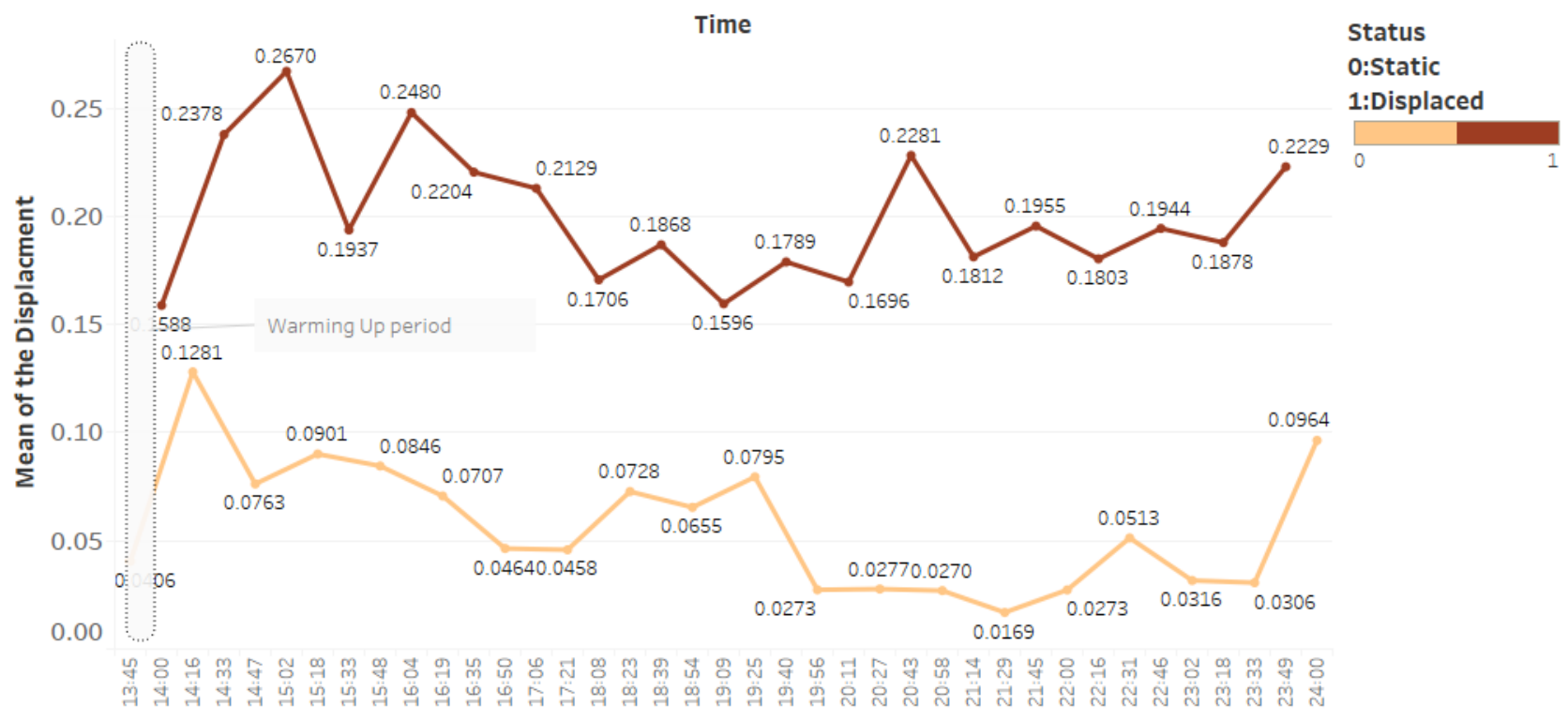

Figure 3: GNSS displacements evolution.

\section{Results and discussions}

This research section is devoted to understanding data trend and direction, data features, and position relations from collected data. Additionally, this section has statistical results driven from collected PPP observations. Table 2 shows the coordinates in ITRF2014 format. The table contains maximum, minimum, standard deviation, and the mean values for the observed coordinates.

True Coordinates values show the coordinates driven from the post-processed static observations. Table 2 also contains the mean, standard deviation, maximum and the minimum of the $X, Y$ and $Z$ residual, which had been getting the differences calculated by the subtraction of each observation coordinate components from the true value. Next, the mean and the standard deviation were calculated from the differences.
Similarly to the previous table, the following statistical results are driven from the observed data in the displaced points. The computation was done in east, north, and up components with respect to a priori station marker coordinates. Table 3 shows the maximum, minimum, and $\mathrm{E}, \mathrm{N}$ and Up displacements values.

Another important aspect we consider to focus on it in future investigations is regarded features engineering. On this characteristic, we will try to trade-off between the numbers of required features and model accuracy. Indeed, this trade-off will improve the model accuracy as well as the performance. For example, the following figures show the total satellite number and the Hdop values along 10 hours of observations; Figure 4 shows the number of satellites during the observation session, this number varies between 9 and 17, and Figure 5 shows the Hdop, which reaches 2.0 value as maximum and 1.3 as the minimum. Hdop and the satellite number was averaged for each hour in Figures 4 and 5. 
Table 2: Experiment statistical summary ITRF2014 Cartesian Coordinates. Units are in meters.

\begin{tabular}{c|c|c|c|c|c} 
Coordinates' components & Mean & Maximum & Minimum & True & $\begin{array}{c}\text { Mean value for the } \\
\text { standard deviation }\end{array}$ \\
\hline X & 4455833.65 & 4455833.996 & 4455833.453 & 4455833.612 & 0.093 \\
Y & 3127063.887 & 3127064.135 & 3127063.682 & 3127063.828 & 0.092 \\
Z & 3314433.218 & 3314433.410 & 3314432.989 & 3314433.169 & 0.086 \\
X residuals & 0.038 & 0.384 & -0.159 & 0.0 & 0.093 \\
Y residuals & 0.058 & 0.306 & -0.146 & 0.0 & 0.093 \\
Z residuals & 0.048 & 0.241 & -0.180 & 0.0 & 0.086
\end{tabular}

Table 3: Experiment statistical summary for displacement values. Units are in meters.

\begin{tabular}{c|c|c|c|c}
$\begin{array}{c}\text { Displacement } \\
\text { components }\end{array}$ & Mean & Max. & Min. & $\begin{array}{c}\text { Mean value } \\
\text { for the } \\
\text { standard } \\
\text { deviation }\end{array}$ \\
\hline E & 0.026 & 0.285 & -0.202 & 0.108 \\
N & 0.007 & 0.232 & -0.272 & 0.102 \\
Up & 0.081 & 0.391 & -0.062 & 0.050
\end{tabular}

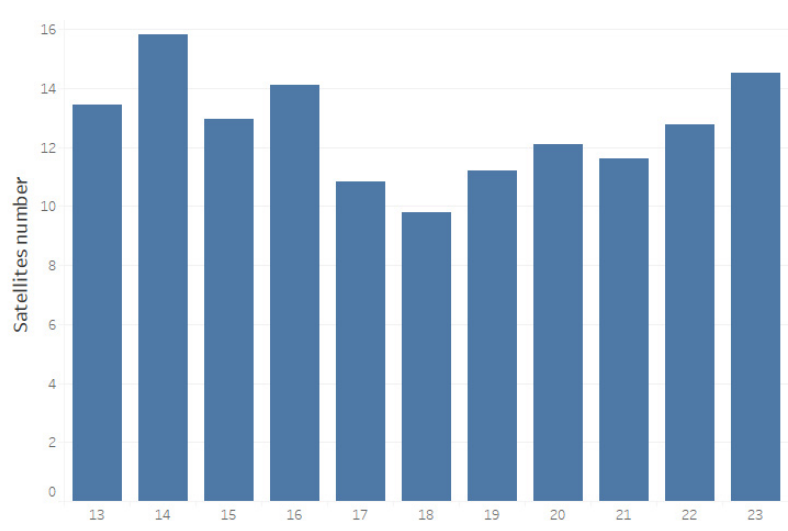

Figure 4: Average number of satellites used in the PPP solutions.

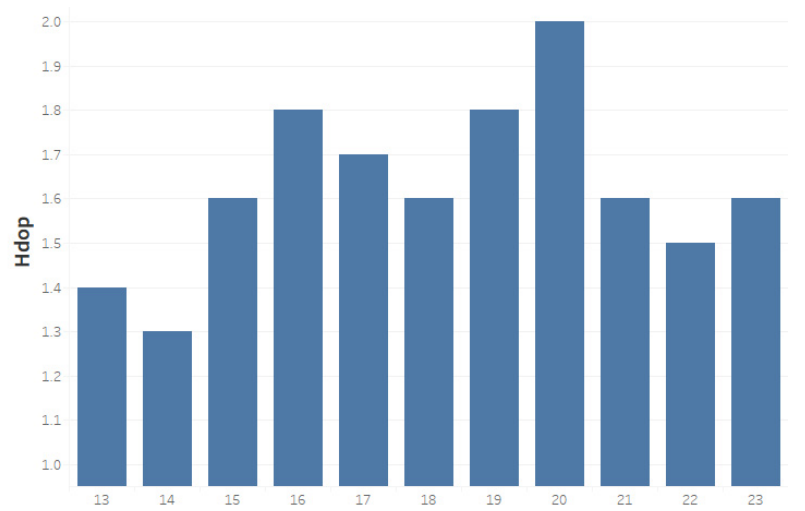

Figure 5: Average value of the horizontal dilution precision.

Figure 6 shows the correlation matrix among different collected features. From the figure, we can observe a correlation between Hdop and the total number of used satellites, as Figures 4 and 5 suggest, and a negative and positive correlation between the phase and code residuals with latency values.

\section{Conclusions}

From Tables 1 and 2, we can conclude that it will be very difficult to accurately observe displacements or deformations below 10 centimetres with the real-time PPP technique.

The study of the different features related to the observations can be used for a machine and deep learning classification, considering only two groups, no deformation and deformation.

For doing this, future investigations will involve adding orbital corrections in terms of radial, long track and out of plane corrections values and velocities as features. Also, many different experiments should be done to generate a big database for training the models and to try to reduce the accurate of the observed deformation to a centrimetric level, so the early warning system proposed can be used for monitoring megastructures deformation, or natural hazards such as earthquakes, and landslides. 


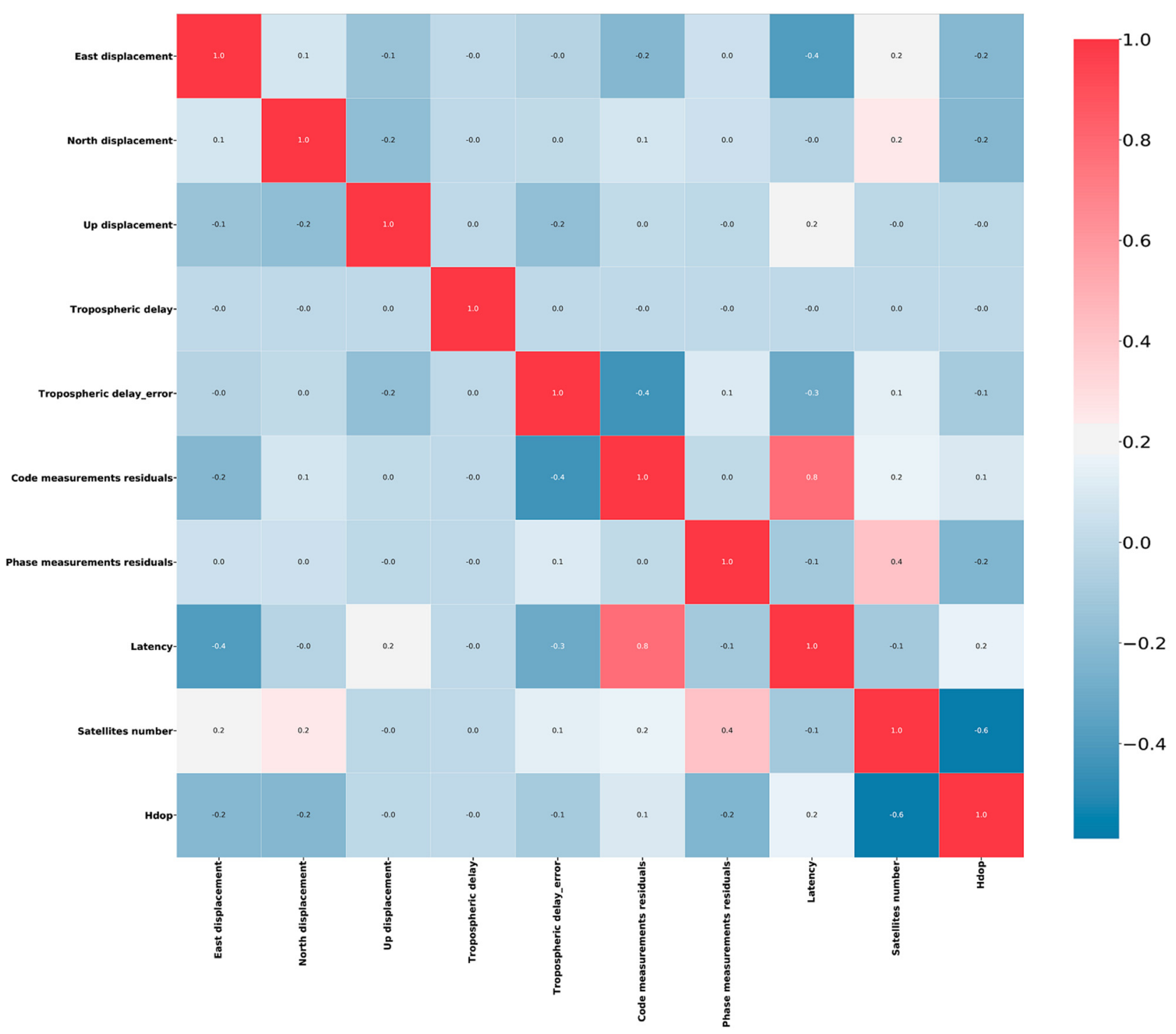

Figure 6: Features correlations matrix.

\section{References}

BARKER, R., LAPUCHA, D., and WOOD, T., 2002. The Impact of High Performance GPS on the Offshore Marine Survey, Navigation and Positioning Industry. Offshore Technology Conference. Houston, Texas: Offshore Technology Conference. DOI: 10.4043/14195-MS

BleWITT, G., HAMMOND, W. C., KREEMER, C., PLAG, H. P., STEIN, S., and OKAL, E., 2009. GPS for real-time earthquake source determination and tsunami warning systems. Journal of Geodesy, 83(3-4), pp. 335-343. DOI: $10.1007 / \mathrm{s} 00190-008-0262-5$

ENGE, P., and MISRA, P., 2011. Global Positioning System: Signals, Measurements, and Performance - Revised Second Edition (2011). International Journal of Wireless Information Networks, 2.

GPS.GOV. 2020. Other Global Navigation Satellite Systems (GNSS). Available: https://www.gps.gov/systems/gnss/ [5/2, 2020].

INTERNATIONAL GNSS SERVICE. 2013. RTS Products - International GNSS Service (igs.org). Available: http://www.igs.org/rts/products [12/16, 2019].

JÄGER, R., KÄLBER, S., OSWALD, M., and BERTGES, M., 2005. GNSS/GPS/LPS based Online Control and Alarm System (GOCA)-Mathematical models and technical realisation of a system for natural and geotechnical deformation monitoring and analysis. In Proceedings of the 2005 Geodetic Deformation Monitoring: From Geophysical to Engineering Roles, IAG Symposium. Jaén, Spain, March, pp. 17-19.

JOHNSTON, G., RIDDELL, A., and HAUSLER, G., 2017. The International GNSS Service. Springer Handbook of Global Navigation Satellite Systems, pp. 967-982. DOI: 10.1007/978-3-319-42928-1_33 
MARTÍN, A., HADAS, T., DIMAS, A., and ANQUELA, A. B., 2013. Influence of real-time products latency on kinematic ppp results. 5th International Colloquium Scientific and Fundamental Aspects of the Galileo Programme. Braunschweig, Germany.

MATPLOTLIP. 2012. Matplotlib: Python plotting - Matplotlib 3.1.2 documentation. Available: https://matplotlib.org/ [1/15, 2020].

NOVATEL INC. 2015. An Introduction to GNSS GPS, GLONASS, BeiDou, Galileo and other Global Navigation Satellite Systems NovAtel. An Introduction to GNSS Book | NovAtel. Available: https://novatel.com/an-introduction-to-gnss $[1 / 15,2020]$

QAFISHEH, M. W. A., MARTÍN, A., and TORRES-SOSPEDRA, J., 2020. Support vector regression machine learning tool to predict GNSS clock corrections in real-time PPP technique. CEUR Workshop Proceedings, 2626.

RIZOS, C., JANSSEN, V., ROBERTS, C., and GRINTER, T., 2012. Precise Point Positioning: Is the era of differential GNSS positioning drawing to an end?

ROBERTS, G., DODSON, A., and ASHKENAZI, V., 1999. Global Positioning System aided autonomous construction plant control and guidance. Automation in Construction, 8(5), pp. 589-595. DOI: 10.1016/S0926-5805(99)00008-4

SCIKIT-LEARN. 2016. scikit-learn: machine learning in Python - scikit-learn 0.22 .1 documentation. Available: https://scikit-learn.org/stable/index.html [1/15, 2020].

STONE, W., 2006. The evolution of the National Geodetic Survey's continuously operating reference station network and online positioning user service. In Proceedings of IEEE/ION PLANS 2006, pp. 653-663.

WEBER, G., and MERVART, L., 2007. The BKG Ntrip Client (BNC). In Report on EUREF symposium.

ZUMBERGE, J. F., HEFLIN, M. B., JEFFERSON, D. C., WATKINS, M. M., and WEBB, F. H., 1997. Precise point positioning for the efficient and robust analysis of GPS data from large networks. Journal of geophysical research: solid earth, 102(B3), pp. 5005-5017. 